\title{
Systematic evaluation of genome-wide methylated DNA enrichment using a CpG island array
}

Liu Yang ${ }^{2,3+}$, Kunlin Zhang ${ }^{1 \dagger}$, Wei Dai ${ }^{2}$, Ximiao He ${ }^{1}$, Qian Zhao ${ }^{1}$, Jing Wang ${ }^{1 *}$, Zhong Sheng Sun ${ }^{2 *}$

\begin{abstract}
Background: Recent progress in high-throughput technologies has greatly contributed to the development of DNA methylation profiling. Although there are several reports that describe methylome detection of whole genome bisulfite sequencing, the high cost and heavy demand on bioinformatics analysis prevents its extensive application. Thus, current strategies for the study of mammalian DNA methylomes is still based primarily on genome-wide methylated DNA enrichment combined with DNA microarray detection or sequencing. Methylated DNA enrichment is a key step in a microarray based genome-wide methylation profiling study, and even for future high-throughput sequencing based methylome analysis.

Results: In order to evaluate the sensitivity and accuracy of methylated DNA enrichment, we investigated and optimized a number of important parameters to improve the performance of several enrichment assays, including differential methylation hybridization (DMH), microarray-based methylation assessment of single samples (MMASS), and methylated DNA immunoprecipitation (MeDIP). With advantages and disadvantages unique to each approach, we found that assays based on methylation-sensitive enzyme digestion and those based on immunoprecipitation detected different methylated DNA fragments, indicating that they are complementary in their relative ability to detect methylation differences.
\end{abstract}

Conclusions: Our study provides the first comprehensive evaluation for widely used methodologies for methylated DNA enrichment, and could be helpful for developing a cost effective approach for DNA methylation profiling.

\section{Background}

The most widely studied epigenetic modification in humans is cytosine methylation at $\mathrm{CpG}$ dinucleotides. Computational analysis predictions have indicated there are about 29,000 CpG islands in the human genome $[1,2]$. Approximately $70 \%$ of CpG dinucleotides in mammals are methylated and found in repetitive elements [3] whereas most CpG islands with relative high densities of unmehylated $\mathrm{CpG}$ dinucleotides are located at the promoter region of house-keeping genes and tumor suppressor genes and play important roles in gene expression regulation and cellular differentiation [4].

\footnotetext{
* Correspondence: wangjing@psych.ac.cn; zsunusa@yahoo.com

+ Contributed equally

'Key Laboratory of Mental Health, Institute of Psychology, Chinese Academy of Sciences, 100101 Beijing, PR China

${ }^{2}$ Behavioral Genetics Center, Institute of Psychology, Chinese Academy of

Sciences, 100101 Beijing, PR China

Full list of author information is available at the end of the article
}

Additionally, researchers have found that DNA methylation changes occur in human cancers [5], and researches in this area have established that hypermethylation of $\mathrm{CpG}$ islands tends to silence tumor suppressor genes and that hypomethylation activates oncogenes [6-8].

Many approaches for detecting DNA methylation are done in a gene-specific manner, such as bisulfite treatment of DNA combined with sequencing, amplification by methylation-specific PCR, or restriction enzymebased digestion. These techniques are limited to study known candidate genes. Recent advances in DNA sequencing methods have now allowed genome-wide DNA methylation studies. However, even with the use of cost-effective next-generation sequencing technologies to carry out these analyses [9-11], there is still heavy reliance on high cost and high computational load of bioinformatics analyses, making sequencing methods still of limited application. Alternative genome-wide

\section{Ciomed Central}


DNA methylation methods based on microarray technologies have proven to be useful. Additionally, due to the methylation patterns of the human genome described above, inclusion of a methylation enrichment approach can be extremely useful for detecting genomewide DNA methylation patterns and changes.

The most popular genome-wide methylated DNA enrichment studies include approaches based on methylation-sensitive restriction-enzyme digestion. These include the following: differential methylation hybridization $(\mathrm{DMH})$, which is a method for comparing the methylation status of $\mathrm{CpG}$ islands between test samples and control samples [12-14] and are widely used [15-22]. Microarray-based methylation assessment of single samples (MMASS), which utilizes methylationsensitive and methylation-dependent enzyme digestion for within-sample comparison of methylation level of CpG island (CGI) loci [23]. Affinity purification by methylcytosine DNA-binding domain (MBD) protein, which uses an MBD-domain-conjugated column to purify methylated DNA fragments for DNA methylation assessment [24]. Immunoprecipitation of DNA using an antibody that recognizes 5'-methyl cytosine (MeDIP) [25-29], which was demonstrated to be more sensitive than MBD purification for detecting methylated DNA [30]. More approaches have also been developed recently [31,32].

Although the above global methylated DNA enrichment assays have demonstrated widespread utility, a systematic analysis of the sensitivity and accuracy of each of these assays has not been performed. In addition, within each method there is considerable variation in the use of each of the experimental parameters, which are important for enhancing the performance and many of them have not been adequately explored. Thus, a systematic evaluation of different approaches for genome-wide methylated DNA enrichment with optimized experimental parameters is necessary.

In this study, we set about to optimize several of the experimental parameters in these methodologies, and then we followed this up by performing a direct comparison between DMH, MMASS, and MeDIP. We additionally assessed potential reasons that underlie the variability in these assays. Our work provides the first results for evaluating these widely used enrichment assays, which will be useful for accurately analyzing the methylome in the epigenomics field.

\section{Results}

\section{Evaluation of the quality of Human 9 K CGI array}

As a first step for our analyses, we assessed the quality of our human 9 K CGI array (see Methods for array construction) as well as the consistency of our labeling. We hybridized two independently labeled aliquots (2 ug each) of sonicated genomic DNA with Cy5 and Cy3 fluorescent dyes, respectively. An MA plot of background-corrected and normalized $\log _{2}$ signal versus $\log _{2}$ differential signal from both the Cy5 and Cy3 channels is shown in Additional file 1, Figure S1-A. The signal consistency of two channels was very high with $>99.5 \%$ of CGI probes showing <2-fold differential expression $(|M|<1)$, and the signal from the two channels manifesting a strong correlation (Pearson correlation coefficient $=0.9975)$, confirming that our array was of high quality for use in the following experiments.

\section{Optimization of experimental parameters in $\mathrm{DMH}$, MMASS, and MeDIP}

DMH, MMASS, and MeDIP all have several parameters that can impact the quality of the results. To provide an assessment of the importance of each parameter and their impact on the experimental results, we investigated and optimized the primary parameters that could impact the results in these analyses. For DMH and MMASS assays, where the digested DNA products are amplified using PCR, the impact of annealing temperature in the PCR amplification of the digested products was assessed, and for MeDIP we looked at the incubation time of the 5-methylcytosine antibodies and secondary antibody during immunoprecipitation.

Methylation profiling of the gastric adenocarcinoma cell line MGC-803 was carried out using our Human 9 K CGI Array. The DNA products, derived from methylation sensitive restriction enzymes BstUI and HpaII (combined and called v1), and the methylation-dependent enzyme McrBC-digestion respectively, were PCRamplified using three different annealing temperatures, $\mathrm{i}$. e. $65^{\circ} \mathrm{C}$ [23], $68.5^{\circ} \mathrm{C}$ (average of $65^{\circ} \mathrm{C}$ and $72^{\circ} \mathrm{C}$ ), and $72^{\circ}$ $\mathrm{C}[12,19]$. We then hybridized equal amounts of the probe on the CGI array for within-sample comparison of methylation levels. Our results revealed that PCRamplification at different annealing temperatures produced different methylation patterns after hybridization. Additional file 1, Figure S1-B shows that the array with an annealing temperature of $72^{\circ} \mathrm{C}$ had a higher total intensity and than the other two. Given this temperature providing the strongest signal, all the following $\mathrm{DMH}$ and MMASS experiments used $72^{\circ} \mathrm{C}$ as the optimal temperature for PCR amplification.

As antibody incubation time played a crucial role in the binding efficiency and specificity of methylated DNA fragments, To assess the specificity and efficiency of the methylated DNA fragment in MeDIP, we utilized two sets of external DNA controls from yeast genomic DNA, which had no significant homology with human and mouse genomic DNA sequence by BLAST (e value $>10^{-3}$ ), and each of the external DNA control was composed of methylated and unmethylated DNA fragments 
with a set ratio (Additional file 1, Table S1, S2) for assessment of optimized incubation time of anti-5methylcytosine Mouse mAb and sheep anti-mouse IgG using a microarray-based methylation profiling study. The first tested condition employed anti-5-methylcytosine Mouse $\mathrm{mAb}$ with a $2 \mathrm{hr}$ incubation time followed by incubation with sheep anti-mouse IgG for $2 \mathrm{hrs}$, as described previously [25]. The results showed that the hybridization ratio of IP compared to input of all the controls was much lower than the theoretical ratio, indicating that the methylated DNA binding with anti-5methylcytosine Mouse mAb antibody was incomplete (Additional file 1, Figure S2 (Top)). We then increased the time of anti-5-methylcytosine Mouse mAb incubation to $12 \mathrm{hrs}$ and found that the binding efficiency of external controls increased but still remained lower than the theoretical ratio shown in Additional file 1, Figure S2 (Top).

Next the impact of the incubation time of the secondary antibody sheep anti-mouse IgG at $1 \mathrm{hr}, 2 \mathrm{hrs}, 4 \mathrm{hrs}$, and $6 \mathrm{hrs}$, was investigated respectively. The results showed the captured amount of methylated DNA increased with longer incubation time of the secondary antibody. However, nonspecific binding of unmethylated DNA fragments also rose (Additional file 1, Figure S2 (middle)). Nevertheless, the growth tendency showed the deviation of each external control from theoretical ratio was lowest around 3 hours. The results demonstrated that the optimal conditions for methylated DNA enrichment in MeDIP was a 12-hr incubation with the primary antibody followed by a $3-\mathrm{hr}$ incubation with the secondary antibody. These optimized conditions were used in all following MeDIP experiments.

We also used our DNA external controls to evaluate the deviation of methylated DNA enrichment among DMH-v2, MMASS-v2, and MeDIP (using a 12-hr primary antibody incubation, and $2 \mathrm{hr}, 3 \mathrm{hr}$, and $4 \mathrm{hr}$ secondary antibody incubation). Our data showed that the deviation from the theoretical ratio of all external DNA controls was lowest for MeDIP (Additional file 1, Figure S2 (Bottom)). This indicates that whole genome amplification after digestion in DMH and MMASS may introduce PCR bias; thus, it is important when using those two assays to take this into consideration for evaluating results.

\section{Systematic comparison of DMH, MMASS, and MeDIP}

After optimization of the above parameters for better performance for all three methods, a systematic evaluation of DMH, MMASS, and MeDIP was carried out using human $9 \mathrm{~K} \mathrm{CpG}$ microarray for detecting differential methylation profiling of the gastric epithelium cell line Ges-1 and the gastric adenocarcinoma cell line MGC-803.

We first compared DMH and MMASS, both of which are based on restriction enzyme digestion. DMH typically employed methylation-sensitive enzyme digestion to enrich the methylated DNA fraction for betweensamples comparison [12,16,18-20], whereas, MMASS used methylation-sensitive and methylation-dependent enzymes digestion for within-sample comparison [23,33].

To evaluate MMASS and DMH assays, McrBC $[23,33,34]$ was used to restrict samples for the representation of unmethylated sequences; the combination of BstUI and HpaII (v1) [12,16,18-20] and the combination of Acil, HinP1I, HpyCH4IV and HpaII (v2) [23,33] were two sets of methylation-sensitive enzymes. Both sets of methylation-sensitive enzymes ( $\mathrm{v} 1$ and $\mathrm{v} 2$ ) were able to interrogate more than 90\% CGI probes on our array, with v2 as high as $98.81 \%$ (Table 1,2). As seen from the $\mathrm{MA}$ and volcano plots, differential expression (M), statistical $B$ value, and $\log _{2}$ fold change of MMASS were much higher than DMH for both v1 and v2 enzyme sets (Figure 1). These data indicate that MMASS has a higher sensitivity than DMH. In addition, MMASS had a higher number of significant candidates $(B$ value $>0$ as cutoff) than did DMH (Figure2-A, B): MMASS-v1 selected 531 differential candidates and MMASS-v2 had 512; whereas DMH-v1 selected 232 and DMH-v2 had 142. The overlap in candidates between DMH and MMASS using enzyme set v1 and set v2 was 144 and

Table 1 Percent of coverage of CGI loci identified from the CGI library and CpGs in the human genome by each methylation-sensitive restriction enzyme

\begin{tabular}{|c|c|c|c|c|c|}
\hline \multirow[t]{2}{*}{ Enzymes } & \multirow[t]{2}{*}{ Recognition sequence } & \multicolumn{2}{|c|}{ Percentage coverage of CGI locis } & \multicolumn{2}{|c|}{ Percentage coverage of $\mathrm{CpGs}$} \\
\hline & & Number & Percent & CGI Library & Whole genome * \\
\hline Hpall (BsiSI) & CCGG & 8,145 & $87.48 \%$ & $11.31 \%$ & $8.60 \%$ \\
\hline Hin6l (HinP1I) & GCGC & 7,877 & $84.60 \%$ & $11.85 \%$ & $6.40 \%$ \\
\hline Acil (Ssil) & CCGC & 8,093 & $86.92 \%$ & $13.10 \%$ & $17.40 \%$ \\
\hline HpyCH4IV & ACGT & 5,261 & $56.50 \%$ & $2.88 \%$ & $6.60 \%$ \\
\hline Bstul & CGCG & 7,154 & $76.83 \%$ & $9.14 \%$ & NA \\
\hline
\end{tabular}

* Percent coverage of CpGs in the whole genome cited from Schumacher et al., 2006, Nucleic Acids Reaserach, 34(2), 528-542, which was based on a representative $100 \mathrm{~Kb}$ of genomic DNA derived from the Chromosome 22 COMT region.

The total number of clones on the array was 9311 and the total number of CpGs in the clones on the array was 311052. 
Table 2 Percent coverage of CGI loci identified from the CGI library using a combintion of enzymes

\begin{tabular}{|c|c|c|c|c|}
\hline \multirow[t]{2}{*}{ Enzymes } & \multicolumn{2}{|c|}{ All Covered ${ }^{1}$} & \multicolumn{2}{|c|}{ Overlapped Covered $^{2}$} \\
\hline & Number & Percentage & Number & Percentage \\
\hline Hpall (BsiSI) + Bstul (v1) & 8,770 & $94.19 \%$ & 6,529 & $70.12 \%$ \\
\hline Hpall (BsiSI) + Hin6l (HinP1I) + Acil (Ssil) + HpyCH4IV (v2) & 9,200 & $98.81 \%$ & 3,885 & $41.72 \%$ \\
\hline
\end{tabular}

${ }^{1}$ All Covered means the clones cover at least one combined enzymes site.

${ }^{2}$ Overlapped Covered means clones cover all combined enzymes sites.

114, respectively. Most of differential candidates detected in DMH were also selected by MMASS, but MMASS characterized an additional number of unique candidates (Figure2-A, B).

To validate the accuracy of the results from the two methods, we used bisulfite sequencing to confirm methylation statue difference in GES and 803 from the unique targets in MMASS-v2 and DMH-v2, and the common targets from both. For this, we randomly tested 25 of the unique MMASS-v2 targets (398 total), 13 of the unique DMH-v2 targets (28 total), and 17 of the candidates common to both (114 total), and obtained validation of $88.00 \%$ of the unique MMASS-v2 candidates, $75.00 \%$ of the unique DMH-v2, and $94.12 \%$ of the candidates common to both (Additional file 1, Figure S3 (Top)). Similar results also could be obtained from v1 set of enzymes that the true positive rates are $85.00 \%$ in MMASS-v1 unique and $96.55 \%$ in common. Thus, the data from the bisulfite sequencing validation indicates that both sensitivity and accuracy in MMASS was higher than the ones in DMH. Although it has been reported that the comparison of methylated to unmethylated DNA within sample in MMASS would amplify the fold change and $B$ value, based on our validation data, the results are relatively reliable.

We also compared results between MMASS with MeDIP, for which, respectively, enrichment is based on methylation-sensitive and -dependent enzymes digestion, and on immunoprecipitation of methylated DNA. The MA and volcano plots of these two assays showed significantly higher differential expression (M), statistical $B$ value, and fold change in MMASS for both v1 or v2 set of enzymes as compared to MeDIP, indicating that the sensitivity of MMASS assay is greater than MeDIP. Additionally, MMASS also identified more candidates showing differential expression compared to MeDIP (Figure2-C). Although enzyme digestion assays do have restriction-site limitations, since even with several enzymes combined the whole genome CGI cannot be covered (shown in Table 1), the MMASS assay still shows an overall better sensitivity than the other two, indicating it likely provides a better representation of the methylation status of target DNA.

We also evaluated the accuracy of the two assays by testing 27 candidates from unique to MMASS-v2 (420 total), 16 candidates unique to MeDIP (92 total), and 16 candidates shared by both (92 total) methods for bisulfite sequencing. The resulting data showed that the true positive rates were $85.71 \%$ for those unique to MMASS-v2, $85.71 \%$ for those unique to MeDIP, and $100.00 \%$ for those in common between the two methods (Additional file 1, Figure S3 (bottom)). Although the sensitivity of MMASS was much higher than MeDIP, the accuracy of both assays was similar.

Considering that MeDIP approach employed Klenow for amplification of purified methylated DNA fragment, it generally has lower amplification efficiency compared with the PCR based amplification employed in DMH and MMASS. Therefore we suspected that the lower sensitivity in MeDIP is due to the low abundance of tested DNA amplicon in MeDIP, which can not be detected by array. Under such perspective, we assessed the efficiency of immunoprecipitation. We used quantitative PCR analysis on 11 randomly selected differential methylated probes in the MGC-803 cell line that were validated by bisulfite sequencing as targets, and the results (Additional file 1, Figure S4-A) showed that MeDIP enriched the majority of the hypermethylated DNA fragments several fold relative to an equal amount of input DNA. We also assessed the enrichment level of these differential methylated clones in the Ges-1 cell line, and the methylation level of Ges-1 compared to MGC-803 was consistent with the results obtained using MMASS-v2 but was very low for MeDIP $(B$ value $<0)$ (Additional file 1, Figure S4-B). Based on these findings, the methylation difference of CGI between the two samples was likely due to the inability of MeDIP enrichment to be thoroughly using CGI array based technology. Given this, we decreased the threshold of the $B$ value to obtain a larger number of differential candidates from the results of MeDIP. With the $B$ value cutoff decreased to $-1,-2,-3,-4,-5$, and -6 , the number of identified differential probes increased to $238,308,418,615,1000$, and 1788. Respectively (Table 3); nevertheless, the relative overlap percentage of MeDIP with both MMASS-v1 and MMASS-v2 decreased gradually (Table 3). Furthermore, we validated the accuracy of newly covered unique differential probes from MeDIP with $B$ value cutoff decreased through bisulfite sequencing. The results demonstrated that the true positive rate is 


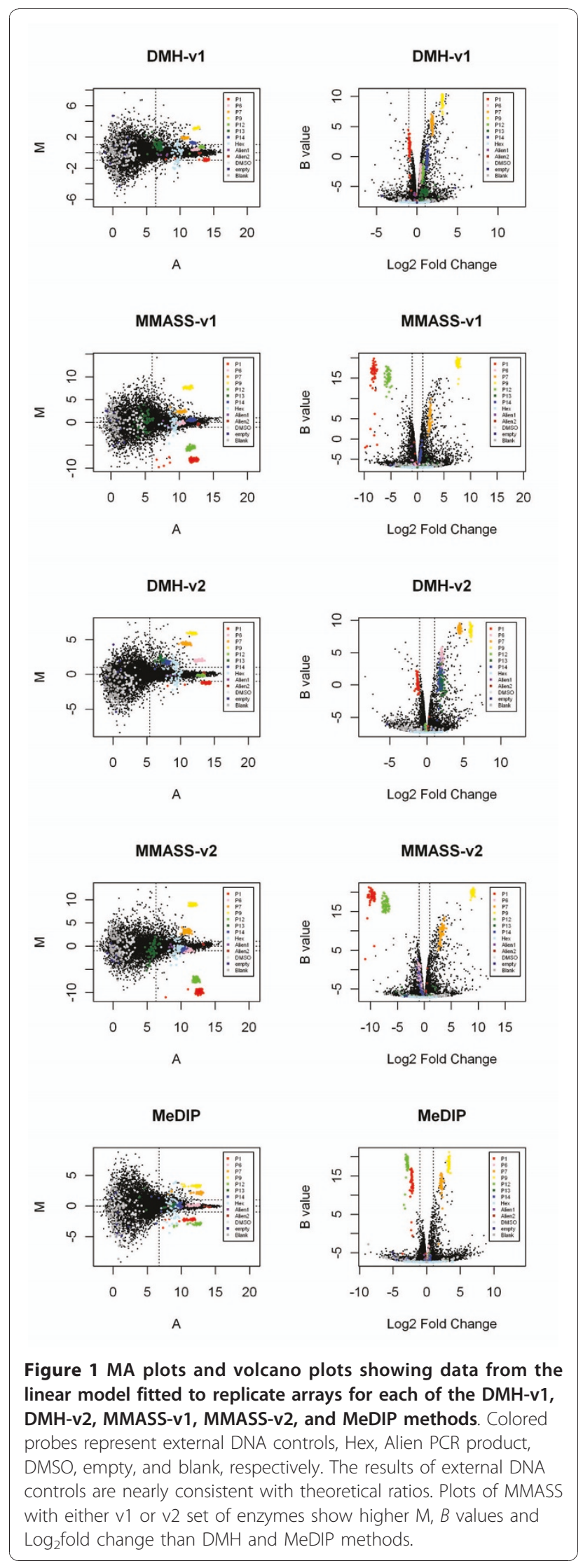

$88.89 \%$ with $-2<B$ value $<0$ which is similar with $85.71 \%$ of $B$ value $>0$, but it sharply descends to $52.17 \%$ as $-4<B$ value $<-2$ (Additional file 1, Figure S5). Therefore, a slight decrease in the $B$ value can compensate for deficiencies the array allowing detection of more differential candidates without substantially affecting accuracy.

\section{Discussion}

Genomic profiling of methylated and unmethylated sequences using methylation-sensitive restriction enzyme digestion or 5'-methylcytosine antibody immunoprecipitation combined with hybridization to microarrays is a potentially powerful and expedient method. However, in contrast to work performed on expression microarray data, so far there has been no detailed assessment of the effects of different parameters or of enrichment assays on the overall results from these methods. Here, we optimized several important parameters to enhance the efficiency of enrichment, and elucidated the sensitivity and specificity of methylationrestriction enzyme-digestion-based methods and 5'methylcytosine immunoprecipitation-based enrichment methods.

Our data showed that the sensitivity of DMH is less than that of MMASS, whereas DMH is complementary to MMASS. MMASS when used in combination with CGI array detection provided the best results for both the sensitivity and accuracy of the three different methylation profiling approaches when using a $B$ value cutoff 0 . The results when using methylated DNA as compared to unmethylated DNA in MMASS also increased the sensitivity of differential methylation detection, and this was primarily because both methylation sensitive and methylation-dependent enzymes are complementary in their ability to identify differential methylation levels in CGI. However, methylation-sensitive restriction enzymes were not able to interrogate every cytosine, and, even when using a combination of four enzymes, more than half of the CpG sites of the genome were missed. Thus, in MMASS, many of the differential CGIs ranked very low as candidates; these candidates, however, could be detected using MeDIP.

The above is likely due to the fact that 5'-methylcytosine antibody binds to methylated DNA throughout the entire genome, making it potentially a better method for detecting genome-wide methylation changes; however, it still has serious limitation in that, whereas it can easily detect methylated DNA where there are two or three methyl moieties per molecular, DNA with only one methyl group is insufficient for detection [26]. Methylated DNA enrichment could potentially aid in overcoming this issue, and our assessment of MeDIP did illustrate that such low copy CGIs could be enriched 
A

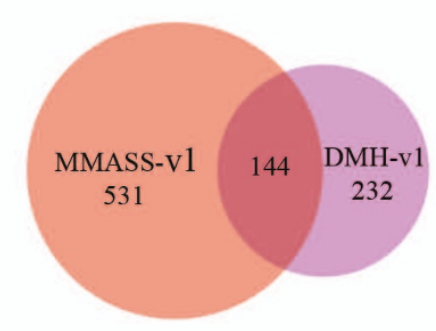

B

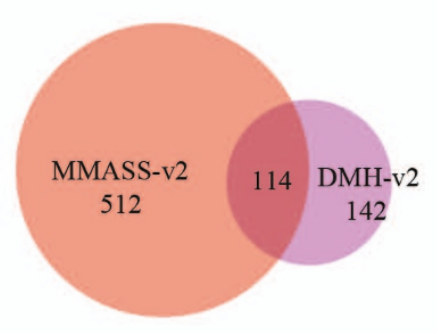

C

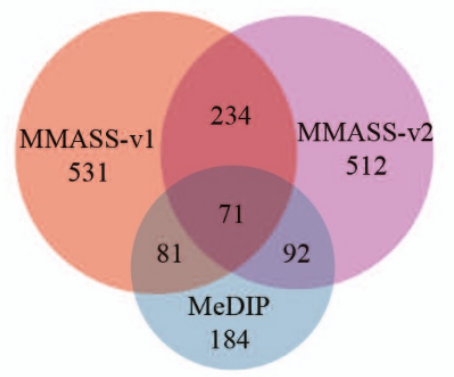

Figure 2 Uniqueness and overlap of differential probes deteced by DMH-v1 versus MMASS-v1, DMH-v2 versus MMASS-v2, and MMASS-v1 and MMASS-v2 versus MeDIP methods, respectively. A greater amount of differential information could be obtained by MMASS compared to DMH and MeDIP using either enzyme sets.

through immunoprecipitaton, they were poorly detected by the CGI array. Using a slightly lower $B$ value cut-off did compensate for this, but lowering the cutoff too far had a drastic negative impact on specificity. Thus, only with very careful adjustment of specific parameters, could MeDIP achieve similar sensitivity and specificity to MMASS. It should also be noted that our study was performed for $\mathrm{CpG}$ islands, hence in $\mathrm{CpG}$-poor regions the performance of the compared methods might differ.

This last finding indicated that, because such care is needed in setting the parameters for MeDIP to obtain good sensitivity without extensive loss of accuracy, that use of more sensitive detection technology such as next generation sequencing (NGS, under the platforms like Illumina Genome Analyzer, Roche/454 FLX, and Applied Biosystems SOLiD ${ }^{\text {tw }}$ system) $[35,36]$, rather than array technology would make this an excellent method for getting at the methylation status of the entire genome. Genome-scale methylation profiling with bisulfite sequencing has been successfully performed in Arabidopsis and mammalian cell line [9,11,37]. Additionally, restriction enzymes have been combined with direct sequencing to determine global methylation patterns in human brain DNA [38]. With the development of high throughput sequencing, it is expected that whole genome methylome sequencing will become an even more effective strategy for whole epigenomic analysis. On the other hand, it should also be noted that although NGS technology with platform such as Illumina Genome Analyzer is not strictly restricted by abundance of DNA fragments and is able to provide whole genome methylation profile at single-nucleotide base resolution, currently the high cost and high computational load of bioinformatics analysis make it still of limited application. Microarray-based technology as we utilized in this work technically requires high abundance of DNA fragments to ensure high signal intensity needed for array and can not reach the resolution of single-nucleotide base, while it has been wellestablished with low cost and mature bioinformatics strategies and is especially applicable to detect methylation profile of specific regions of interest (e.g. CpG islands). Thus, NGS and microarray DNA methylation profiling methods are expected to co-exist to fulfill the demands of different researches in future [39]. The enrichment methods we evaluated in our work could be employed to enrich specific methylated genomic regions of interest for both microarray technology and NGS technology to investigate DNA methylation profiling.

\section{Conclusions}

Our results show that assays based on methylationsensitive enzyme digestion and those based on immunoprecipitation detected different methylated DNA fragments, indicating that they are complementary in their relative ability to detect methylation differences. Our study provides the first comprehensive evaluation for widely used methodologies for methylated DNA enrichment, and could be helpful for developing a cost effective approach for DNA methylation profiling.

Table 3 Overlapped differential probes of MeDIP with MMASS-v1 and MMASS-v2 with a decreasing B value cutoff

\begin{tabular}{|c|c|c|c|c|c|c|c|}
\hline$B$ value (MeDIP) & $>0$ & $>-1$ & $>-2$ & $>-3$ & $>-4$ & $>-5$ & $>-6$ \\
\hline Overlapped probes with MMASS-v1\&MMASS-v2 & 102 & 123 & 148 & 182 & 231 & 289 & 389 \\
\hline Total differential probes & 184 & 238 & 308 & 418 & 615 & 1000 & 1788 \\
\hline Percentage & $55.43 \%$ & $51.68 \%$ & $48.05 \%$ & $43.54 \%$ & $37.56 \%$ & $28.90 \%$ & $21.76 \%$ \\
\hline
\end{tabular}




\section{Methods}

\section{CGI Library, sequencing and CGI array construction}

The CGI Library was obtained from the Wellcome Trust Sanger Institute (Cambridge, UK). The library preparation was as described [40]. Library aliquots were grown in LB media plus ampicillin and plated on LB agar plates plus ampicillin. 17,606 individual clones were picked into 96-well plates containing $600 \mathrm{ul}$ of LB plus ampicillin. Clones were grown in culture overnight at $37^{\circ} \mathrm{C}$ with shaking, followed by $50 \mathrm{ul}$ of culture diluted with glycerol to a final concentration of $30 \%$ as stock solution kept at $-80^{\circ} \mathrm{C}$ for later use. The remaining culture was used for plasmid DNA purification. Plasmid DNA was bi-directionally sequenced on MegaBACE DNA sequencer at the Beijing Genomics Institute, and BLAST was used to map the resulting sequences to the human genome (NIH 36.1). We also collected 6,445 unique clones from the $\mathrm{CpG}$ Island Tagging Project data of Wellcome Trust Sanger Institute http://www. sanger.ac.uk/HGP/cgi.shtml. Unique clones from two batches that overlapped with computational predictions of the whole genome CGI were selected and amplified by PCR for CGI array construction [41]. All purified PCR products from 9,223 CGI clones were sent to the CapitalBio Company for array spotting. Each clone was spotted in triplicate, and the whole array was composed of 48 blocks. In addition to CGI clones, external DNA controls, hexachloro-fluorescein (HEX), and Alien PCR product were placed in the first line of each block and negative controls such as DMSO, empty, and blank wells were also included in the array.

\section{Target probe preparation}

Based on different combination of methylation-sensitive enzyme digestion, DMH-v1 and DMH-v2 methods were employed to enrich methylated DNA fragments for between-sample comparison [19], whereas MMASS-v1 and MMASS-v2 methods used methylation-sensitive and methylation-dependent enzyme digestion for within-sample comparison [23]. In both DMH and MMASS methods, 2 ug of genomic DNA were digested with MseI overnight at $37^{\circ} \mathrm{C}$. The digested DNA was then ligated to the linkers H-14 (5'-tactccctcggata-3') and H-24 (5'-aggcaactgtgctatccgagggag-3') after purification using a Qiaquick PCR purification column (Qiagen, Germany). For enrichment of methylated DNA fraction (common in DMH and MMASS), half of the sample was digested with either a combination of BstUI and HpaII (v1) or a combination of AciI, HinP1I, HpyCH4IV, and HpaII (v2). For enrichment of the unmethylated DNA fraction in MMASS, half of the sample was digested with McrBC. PCR amplification of each enriched DNA fragment was performed in a $300 \mathrm{ul}$ volume mixture comprised of the restriction DNA product, 10× ThermoPol Buffer, $2.5 \mathrm{uM} \mathrm{H}-24$ primer, $0.2 \mathrm{mM}$ dNTP mixture, and $12 \mathrm{U}$ Deep Vent(exo-) DNA polymerase (New England Biolabs, USA). The amplification conditions were $5 \mathrm{~min}$ at $72^{\circ} \mathrm{C}$ to fill in the protruding ends of the ligated DNA fragments, followed by 20 cycles $\left(1 \mathrm{~min}\right.$ at $97^{\circ} \mathrm{C}$ and $3 \mathrm{~min}$ at $72^{\circ}$ $\mathrm{C})$, with a final extension for $10 \mathrm{~min}$ at $72^{\circ} \mathrm{C}$. Ten ul of the PCR product underwent electrophoresis on a $1.5 \%$ agarose gel, with a smear between 0.2 and $2 \mathrm{~kb}$ indicating successful procedure performance during enrichment, as described previously [19]. MeDIP (5'methylcytosine antibody) was employed to immunoprecipitate methylated DNA. $6.5 \mathrm{ug}$ of genomic DNA underwent sonication into random fragments ranging in size from 200 to $1,000 \mathrm{bp}$. The performance procedures of MeDIP were similar to those as described in the work of Weber et al [25]. Briefly, sonicated DNA was denatured at $95^{\circ} \mathrm{C}$ for $10 \mathrm{~min}$, then immunoprecipitated with 10 ul of monoclonal antibody against 5-methylcytosine (Merk, USA) to a final volume of $500 \mathrm{ul}$ of IP buffer (10 mM sodium phosphate ( $\mathrm{pH} 7.0), 140 \mathrm{mM} \mathrm{NaCl}$, $0.05 \%$ Triton $\mathrm{X}-100)$ for 2 and $12 \mathrm{~h}$ at $4^{\circ} \mathrm{C}$, respectively. Then the mixture was incubated with 30 ul of Dynabeads with M-280 sheep antibody to mouse IgG (Dynal Biotech) for $1,2,4$, and $6 \mathrm{~h}$ at $4^{\circ} \mathrm{C}$, respectively and washed $3 \times$ with 700 ul of IP buffer. The sample was incubated with proteinase $\mathrm{K}$ for $3 \mathrm{~h}$ at $50^{\circ} \mathrm{C}$, and the methylated DNA was recovered by phenol-chroloform extraction followed by ethanol precipitation.

\section{CGI array hybridization and microarray data processing}

For DMH and MMASS, 600 ng of each amplicon was labeled with Cy3/Cy5-dCTP (Amersham, USA) (0.24 $\mathrm{mM}$ of each dATP, dGTP, dTTP, $0.12 \mathrm{mM}$ of dCTP and $0.12 \mathrm{mM}$ of Cy3-dCTP or Cy5-dCTP) by random priming. For MeDIP, $1.5 \mathrm{ug}$ of sonicated input DNA and the product of MeDIP (about $400 \mathrm{ng}$ ) were labeled with Cy3/Cy5-dCTP. The Cy3- and Cy5-labeled probes were purified with QIAquick PCR purification kit (Qiagen, Germany), mixed with yeast tRNA (20 ug) and Cot1 (10 ug), and reduced to a volume of $18.4 \mathrm{ul}$ via speed vacuum. After denaturation $\left(5 \mathrm{~min}\right.$ at $\left.95^{\circ} \mathrm{C}\right)$, hybridization buffer pre-warmed to $42^{\circ} \mathrm{C}$ (40 ul of formamide (Sigma, USA), 12 ul of $20 \times$ SSC (Amersham, USA), $1.6 \mathrm{ul}$ of 10\% SDS (Amersham, USA), and $8 \mathrm{ul}$ of $50 \times$ Danhart's (Amersham, USA)) was added into the probe mixture to a final volume of 80 ul. Hybridization of the CGI array was performed under a cover slip in a humidified chamber fixed in a BioMix II hybridization machine (CapitalBio, China) at $42^{\circ} \mathrm{C}$ for $17 \mathrm{~h}$. The array was washed two times in $2 \times$ saline sodium citrate and $0.2 \% \mathrm{SDS}$ at $42^{\circ} \mathrm{C}$ for $5 \mathrm{~min}$ and once in $0.1 \times$ saline sodium citrate at room temperature. The slides were dried by centrifugation at $800 \mathrm{rpm}$ for $5 \mathrm{~min}$ and 
scanned immediately with LuxScan $10 \mathrm{~K}$ scanner (CapitalBio, China). Image analysis was performed with LuxScan $10 \mathrm{~K}$ software (CapitalBio, China) and the raw data was exported as lsr file for subsequent data analysis.

The median average intensity of foreground and background was extracted from the lsr files. If a spot intensity was zero or negative after background subtraction, it was set at half of the minimum positive corrected intensities in the array [42]. We performed normalization using the spike probes that were previously shown to have a consistent log-ratio [43]. Then linear model and empirical Bayes smoothing analyses were combined to obtain the $B$-statistic (lods or $B$, i.e. the log-odds that the CpG island is differentially methylated) and fold change of each spot [44]. Significant candidates were selected with values of $B>0$. All of above calculations were performed using limma http://bioinf.wehi.edu.au/ limma/ package within the R environment http://cran.rproject.org/.

\section{Bisulfite genomic sequencing}

Genomic DNA was treated with EZ DNA MethylationGold $\mathrm{Kit}^{\mathrm{tm}}$ (Company, USA). All the CGIs of differential candidates were amplified with nested PCR. All primer information can be obtained in the supplementary information. The PCR products were gel extracted with QIAquick Gel Extraction Kit (Qiagen, Germany) and cloned into a TA cloning vector according to the manufacturer's instructions (pGEM-T-Easy cloning kit; Promega, USA). At least ten positive clones for each candidate were picked for sequencing. The methylation status of individual CpG sites was determined by comparison of the sequencing results with the original target sequence using CpGViewer software [45].

\section{Quantitative PCR validation}

To assess the immunoprecipitation efficiency, primers were designed to amplify 90 150-bp fragments from differentially methylated regions which were not identified by MeDIP but identified by MMASS. Differentially methylated regions identified by both MeDIP and MMASS were chosen as controls. Equal amounts of methylated DNA enriched from immunoprecipitation and original input DNA were used as templates, respectively. Each plate of PCR reactions included $\beta$-Actin as an internal control, and at least three biological replicates were tested. In total, 11 CGI regions (8 cases and 3 controls) were tested for validation.

\section{Data Access}

All the CpG island array data reported in this work is publicly available at Gene Expression Omnibus http:// www.ncbi.nlm.nih.gov/geo/ with accession number GSE19974.

\section{Additional material}

Additional file 1: Figure S1-S5 and Table S1-S2. This file contains

Figure S1-S5 and Table S1-S2.

\section{Acknowledgements}

This work was sponsored by the National High Technology Research and Development Program of China (863 Program) (Grant No. 2006AA02A304, to ZSS) from the Ministry of Science and Technology of the People's Republic of China; the National Natural Science Foundation of China (NSFC) (Grant No. 30221004, to ZSS); the Innovation Project of Chinese Academy of Sciences (KSCX2-YW-R-38, to ZSS); and Project for Young Scientists Fund, Institute of Psychology, Chinese Academy of Sciences (O9CX115011, to KZ). Funding to pay the Open Access publication charges for this article was also provided by the 863 grant. We thank Dr Laurie Goodman for her helpful suggestions to help us refine the manuscript. We also thank all staffs at Institute of Psychology, Chinese Academy of Sciences, for their sincere supports. We thank the anonymous reviewers for kind comments.

\section{Author details}

${ }^{1}$ Key Laboratory of Mental Health, Institute of Psychology, Chinese Academy of Sciences, 100101 Beijing, PR China. ${ }^{2}$ Behavioral Genetics Center, Institute of Psychology, Chinese Academy of Sciences, 100101 Beijing, PR China. ${ }^{3}$ Zhejiang University School of Medicine, 310058 Hangzhou, PR China.

\section{Authors' contributions}

ZSS and JW managed the project; LY and ZSS designed the experiments; LY and WD performed the experiments; $K Z, X H$ and $Q Z$ analyzed the data; $L Y$, KZ, JW and ZSS wrote the paper. All authors read and approved the final manuscript.

\section{Competing interests}

The authors declare that they have no competing interests.

Received: 8 June 2010 Accepted: 6 January 2011

Published: 6 January 2011

\section{References}

1. Lander ES, Linton LM, Birren B, Nusbaum C, Zody MC, Baldwin J, Devon K, Dewar K, Doyle M, FitzHugh W, et al: Initial sequencing and analysis of the human genome. Nature 2001, 409(6822):860-921.

2. Venter JC, Adams MD, Myers EW, Li PW, Mural RJ, Sutton GG, Smith HO, Yandell M, Evans CA, Holt RA1, et al: The sequence of the human genome. Science 2001, 291(5507):1304-1351.

3. Turker MS, Bestor TH: Formation of methylation patterns in the mammalian genome. Mutat Res 1997, 386(2):119-130.

4. Bird A: DNA methylation patterns and epigenetic memory. Genes Dev 2002, 16(1):6-21.

5. Feinberg AP, Vogelstein B: Hypomethylation distinguishes genes of some human cancers from their normal counterparts. Nature 1983, 301(5895):89-92.

6. Ehrlich M: DNA methylation in cancer: too much, but also too little. Oncogene 2002, 21(35):5400-5413.

7. Feinberg AP, Tycko B: The history of cancer epigenetics. Nat Rev Cancer 2004, 4(2):143-153.

8. Doi A, Park IH, Wen B, Murakami P, Aryee MJ, Irizarry R, Herb B, LaddAcosta C, Rho J, Loewer S, et al: Differential methylation of tissue- and cancer-specific CpG island shores distinguishes human induced pluripotent stem cells, embryonic stem cells and fibroblasts. Nat Genet 2009, 41(12):1350-1353.

9. Ball MP, Li JB, Gao Y, Lee JH, LeProust EM, Park IH, Xie B, Daley GQ, Church GM: Targeted and genome-scale strategies reveal gene-body methylation signatures in human cells. Nat Biotechnol 2009, 27(4):361-368.

10. Deng J, Shoemaker R, Xie B, Gore A, LeProust EM, Antosiewicz-Bourget J, Egli D, Maherali N, Park $H_{1}, Y u$ J, et al: Targeted bisulfite sequencing reveals changes in DNA methylation associated with nuclear reprogramming. Nat Biotechnol 2009, 27(4):353-360. 
11. Lister R, O'Malley RC, Tonti-Filippini J, Gregory BD, Berry CC, Millar AH, Ecker JR: Highly integrated single-base resolution maps of the epigenome in Arabidopsis. Cell 2008, 133(3):523-536.

12. Huang TH, Perry MR, Laux DE: Methylation profiling of CpG islands in human breast cancer cells. HumMolGenet 1999, 8(3):459-470.

13. Yan PS, Wei SH, Huang TH: Differential methylation hybridization using CpG island arrays. Methods Mol Biol 2002, 200:87-100.

14. Yan PS, Potter D, Deatherage DE, Huang TH, Lin S: Differential methylation hybridization: profiling DNA methylation with a high-density CpG island microarray. Methods Mol Biol 2009, 507:89-106.

15. Potter DP, Yan P, Huang TH, Lin S: Probe signal correction for differential methylation hybridization experiments. BMC Bioinformatics 2008, 9:453.

16. Yan PS, Perry MR, Laux DE, Asare AL, Caldwell CW, Huang TH: CpG island arrays: an application toward deciphering epigenetic signatures of breast cancer. ClinCancer Res 2000, 6(4):1432-1438

17. Day JK, Bauer AM, DesBordes C, Zhuang Y, Kim BE, Newton LG, Nehra V, Forsee KM, MacDonald RS, Besch-Williford C, et al: Genistein alters methylation patterns in mice. J Nutr 2002, 132(8 Suppl):2419S-2423S.

18. Yan PS, Chen CM, Shi H, Rahmatpanah F, Wei SH, Huang TH: Applications of CpG island microarrays for high-throughput analysis of DNA methylation. JNutr 2002, 132(8 Suppl):2430S-2434S.

19. Yan PS, Efferth T, Chen HL, Lin J, Rodel F, Fuzesi L, Huang TH: Use of CpG island microarrays to identify colorectal tumors with a high degree of concurrent methylation. Methods 2002, 27(2):162-169.

20. Wei SH, Chen CM, Strathdee G, Harnsomburana J, Shyu CR, Rahmatpanah F, Shi H, Ng SW, Yan PS, Nephew KP, et al: Methylation microarray analysis of late-stage ovarian carcinomas distinguishes progression-free survival in patients and identifies candidate epigenetic markers. ClinCancer Res 2002, 8(7):2246-2252

21. Smirnoff $P$, Liel $Y$, Gnainsky J, Shany S, Schwartz B: The protective effect of estrogen against chemically induced murine colon carcinogenesis is associated with decreased CpG island methylation and increased mRNA and protein expression of the colonic vitamin D receptor. Oncol Res 1999, 11(6):255-264

22. Yan PS, Chen CM, Shi H, Rahmatpanah F, Wei SH, Caldwell CW, Huang TH: Dissecting complex epigenetic alterations in breast cancer using CpG island microarrays. Cancer Res 2001, 61(23):8375-8380.

23. Ibrahim AE, Thorne NP, Baird K, Barbosa-Morais NL, Tavare S, Collins VP Wyllie AH, Arends MJ, Brenton JD: MMASS: an optimized array-based method for assessing CpG island methylation. Nucleic Acids Res 2006, 34(20):e136

24. Lopez-Serra L, Ballestar E, Fraga MF, Alaminos M, Setien F, Esteller M: A profile of methyl-CpG binding domain protein occupancy of hypermethylated promoter CpG islands of tumor suppressor genes in human cancer. Cancer Res 2006, 66(17):8342-8346.

25. Weber M, Davies JJ, Wittig D, Oakeley EJ, Haase M, Lam WL, Schubeler D: Chromosome-wide and promoter-specific analyses identify sites of differential DNA methylation in normal and transformed human cells. NatGenet 2005, 37(8):853-862.

26. Keshet I, Schlesinger Y, Farkash S, Rand E, Hecht M, Segal E, Pikarski E, Young RA, Niveleau A, Cedar $\mathrm{H}$, et al: Evidence for an instructive mechanism of de novo methylation in cancer cells. NatGenet 2006, 38(2):149-153

27. Mohn F, Weber M, Schubeler D, Roloff TC: Methylated DNA immunoprecipitation (MeDIP). Methods Mol Biol 2009, 507:55-64.

28. Jacinto FV, Ballestar E, Esteller M: Methyl-DNA immunoprecipitation (MeDIP): hunting down the DNA methylome. Biotechniques 2008, 44(1):35, 37, 39 passim.

29. Vucic EA, Wilson IM, Campbell JM, Lam WL: Methylation analysis by DNA immunoprecipitation (MeDIP). Methods Mol Biol 2009, 556:141-153.

30. Zhang X, Yazaki J, Sundaresan A, Cokus S, Chan SW, Chen H, Henderson IR, Shinn P, Pellegrini M, Jacobsen SE, et al: Genome-wide high-resolution mapping and functional analysis of DNA methylation in arabidopsis. Cell 2006, 126(6):1189-1201.

31. Pfister S, Schlaeger C, Mendrzyk F, Wittmann A, Benner A, Kulozik A Scheurlen W, Radlwimmer B, Lichter P: Array-based profiling of referenceindependent methylation status (aPRIMES) identifies frequent promoter methylation and consecutive downregulation of ZIC2 in pediatric medulloblastoma. Nucleic Acids Res 2007, 35(7):e51.

32. Kamalakaran S, Kendall J, Zhao X, Tang C, Khan S, Ravi K, Auletta T, Riggs M, Wang Y, Helland A, et al: Methylation detection oligonucleotide microarray analysis: a high-resolution method for detection of $\mathrm{CpG}$ island methylation. Nucleic Acids Res 2009, 37(12):e89.

33. Schumacher A, Kapranov P, Kaminsky Z, Flanagan J, Assadzadeh A, Yau P, Virtanen C, Winegarden N, Cheng J, Gingeras T, et al: Microarray-based DNA methylation profiling: technology and applications. Nucleic Acids Res 2006, 34(2):528-542.

34. Nouzova M, Holtan N, Oshiro MM, Isett RB, Munoz-Rodriguez JL, List AF, Narro ML, Miller SJ, Merchant NC, Futscher BW: Epigenomic changes during leukemia cell differentiation: analysis of histone acetylation and cytosine methylation using CpG island microarrays. JPharmacolExpTher 2004, 311(3):968-981.

35. Shendure J, Ji H: Next-generation DNA sequencing. Nat Biotechnol 2008, 26(10):1135-1145.

36. Mardis ER: Next-generation DNA sequencing methods. Annu Rev Genomics Hum Genet 2008, 9:387-402.

37. Meissner A, Mikkelsen TS, Gu H, Wernig M, Hanna J, Sivachenko A, Zhang X, Bernstein BE, Nusbaum C, Jaffe DB, et al: Genome-scale DNA methylation maps of pluripotent and differentiated cells. Nature 2008 454(7205):766-770

38. Rollins RA, Haghighi F, Edwards JR, Das R, Zhang MQ, Ju J, Bestor TH: Large-scale structure of genomic methylation patterns. Genome Res 2006, 16(2):157-163

39. Hurd PJ, Nelson CJ: Advantages of next-generation sequencing versus the microarray in epigenetic research. Brief Funct Genomic Proteomic 2009, 8(3):174-183.

40. Cross SH, Charlton JA, Nan X, Bird AP: Purification of CpG islands using a methylated DNA binding column. NatGenet 1994, 6(3):236-244.

41. Takai $D$, Jones PA: Comprehensive analysis of CpG islands in human chromosomes 21 and 22. ProcNat/AcadSciUSA 2002, 99(6):3740-3745.

42. Ritchie ME, Silver J, Oshlack A, Holmes M, Diyagama D, Holloway A, Smyth GK: A comparison of background correction methods for twocolour microarrays. Bioinformatics 2007, 23(20):2700-2707.

43. Smyth GK, Speed T: Normalization of cDNA microarray data. Methods 2003, 31(4):265-273

44. Smyth GK: Linear models and empirical bayes methods for assessing differential expression in microarray experiments. StatApp/GenetMolBiol 2004, 3:Article3.

45. Carr IM, Valleley EM, Cordery SF, Markham AF, Bonthron DT: Sequence analysis and editing for bisulphite genomic sequencing projects. Nucleic Acids Res 2007, 35(10):e79.

doi:10.1186/1471-2164-12-10

Cite this article as: Yang et al: Systematic evaluation of genome-wide methylated DNA enrichment using a CpG island array. BMC Genomics 2011 12:10

\section{Submit your next manuscript to BioMed Central and take full advantage of:}

- Convenient online submission

- Thorough peer review

- No space constraints or color figure charges

- Immediate publication on acceptance

- Inclusion in PubMed, CAS, Scopus and Google Scholar

- Research which is freely available for redistribution

Submit your manuscript at www.biomedcentral.com/submit
C Biomed Central 